\title{
Beliefs About Willpower Are Related to Therapy Adherence and Psychological Adjustment in Patients With Type 2 Diabetes
}

\author{
Bernecker, Katharina ; Job, Veronika
}

\begin{abstract}
Research suggests that self-control, the ability to forego immediate needs for the sake of future rewards, promotes health behavior. The present study examined the role of beliefs about willpower as predictor of self-control in the context of diabetes. Seventy-nine type 2 diabetes patients reported their beliefs about willpower, therapy adherence (i.e., self-care activities, diet, exercise), and psychological adjustment (i.e., emotional distress, well-being, life quality). Endorsing the belief that willpower is a lim- ited versus nonlimited resource was associated with lower therapy adherence and lower psychological adjustment. How people think about their willpower might be crucial for therapy success in diabetes patients.
\end{abstract}

DOI: https://doi.org/10.1080/01973533.2015.1049348

Posted at the Zurich Open Repository and Archive, University of Zurich

ZORA URL: https://doi.org/10.5167/uzh-114066

Journal Article

Originally published at:

Bernecker, Katharina; Job, Veronika (2015). Beliefs About Willpower Are Related to Therapy Adherence and Psychological Adjustment in Patients With Type 2 Diabetes. Basic and Applied Social Psychology, 37:188-195.

DOI: https://doi.org/10.1080/01973533.2015.1049348 
RUNNING HEAD: WILLPOWER THEORIES AND DIABETES

Beliefs About Willpower are Related to Therapy Adherence and Psychological Adjustment in Patients with Type 2 Diabetes

Katharina Bernecker

Veronika Job

University of Zurich

Author Note

Katharina Bernecker, Veronika Job, Department of Psychology, University of Zurich, Switzerland. Correspondence concerning this article should be addressed to Veronika Job, University of Zurich, Department of Psychology, Binzmuehlestrasse 14/6, 8050 Zurich, Switzerland, email: v.job@psychologie.uzh.ch.

The authors agree to comply with the data-sharing standard of the APA (Ethical Standard 8.14) and provide public access to their data.

This research was funded by the Swiss National Science Foundation (grant number PZ00P1_131858). 


\title{
WILLPOWER THEORIES AND DIABETES
}

\begin{abstract}
Research suggests that self-control, the ability to forego immediate needs for the sake of future rewards, promotes healthy behavior. The present study examined the role of beliefs about willpower, as predictor of self-control, in the context of diabetes. Seventy-nine type 2 diabetes patients reported their beliefs about willpower, therapy adherence (i.e., self-care activities, diet, exercise), and psychological adjustment (i.e., emotional distress, well-being, life quality). Endorsing the belief that willpower is a limited versus nonlimited resource was associated with lower therapy adherence and lower psychological adjustment. How people think about their willpower might be crucial for therapy success in diabetes patients.
\end{abstract}




\section{WILLPOWER THEORIES AND DIABETES}

\section{Beliefs About Willpower are Related to Therapy Adherence and Psychological Adjustment in Patients with Type 2 Diabetes}

Diabetes is one of the most common chronic diseases today. In 2010 the global prevalence was estimated to be 285 million adults (Shaw, Sicree, \& Zimmet, 2010). It is projected that until 2030 the number will increase by another $69 \%$ to 439 million (Shaw et al., 2010). Diabetes is a metabolic disease in which the natural regulation of blood sugar levels is impaired resulting in chronically high blood sugar levels (American Diabetes Association, 2008). To control their blood sugar levels patients have to adhere to a complex therapy throughout their entire life (American Diabetes Association, 2008). The daily prescription typically involves regular blood sugar testing, taking medication, following a low-glycemic diet, and engaging in physical exercise (Boule, Haddad, Kenny, Wells, \& Sigal, 2001; Brand-Miller, Petocz, Hayne, \& Colagiuri, 2003; Turner, Cull, \& Frighi, 1999). Good glycemic control is associated with lower risk for short-term complications (e.g., hyperglycemia), long-term co-morbid conditions (e.g., cardiovascular disease), and mortality (Andersson \& Svärdsudd, 1995; Klein, Klein, \& Moss, 1996). Further, patients with good glycemic control report better life quality and higher subjective well-being (Rubin \& Peyrot, 1999; Van der Does et al., 1996).

Despite the importance of glycemic control for their physical condition and psychological adjustment patients often fail to change their life style and adhere to their therapy. From a motivational perspective the problem of therapy adherence reflects a typical self-control conflict between short-term, hedonic motives and long-term, rational goals (Fujita, 2011; Mann, de Ridder, \& Fujita, 2013). People with diabetes have to engage in unpleasant activities (e.g., blood sugar monitoring, physical exercise) or refrain from pleasant activities (e.g., eating highglycemic foods) to achieve better health outcomes in the future. Self-control is the ability to 


\section{WILLPOWER THEORIES AND DIABETES}

consciously monitor and alter one's own thoughts, emotions, and behavior in order to pursue future goals (Baumeister, Vohs, \& Tice, 2007). There is abundant evidence for the positive relationship between self-control and a broad range of desirable outcomes. For instance, selfcontrol has been found to predict occupational success, stable social relationships, as well as physical health (Finkel, DeWall, Slotter, Oaten, \& Foshee, 2009; Moffitt et al., 2011; Shoda, Mischel, \& Peake, 1990). Further, studies found self-control to be positively associated with psychological adjustment and subjective well-being, which is perhaps due to its effects on these important life outcomes (de Ridder, Lensvelt-Mulders, Finkenauer, Stok, \& Baumeister, 2012; Hofmann, Luhmann, Fisher, Vohs, \& Baumeister, 2013; Tangney, Baumeister, \& Boone, 2004).

Given the large body of research on self-control in general, and within the health context in specific, it is surprising that few studies investigated self-control as predictor for therapy adherence in chronic diseases. Instead, the great majority of studies focuses on eating behavior and physical exercise within the general population (Adriaanse, Kroese, Gillebaart, \& De Ridder, 2014; Fishbach \& Shah, 2006; Hofmann, Gschwendner, Friese, Wiers, \& Schmitt, 2008; Stadler, Oettingen, \& Gollwitzer, 2010). One exception is a study on self-control and therapy adherence (i.e., dieting, exercise, smoker status) among heart surgery patients (Schroder \& Schwarzer, 2005). In this study self-control predicted therapy adherence before surgery and dieting in patients with moderate dieting intentions 6 months after surgery (Schroder \& Schwarzer, 2005).

The aim of the present study was to investigate how individual differences which affect people's self-control relate to therapy adherence and psychological adjustment in people with type 2 diabetes. More specifically, we investigate whether people's beliefs_-or implicit theories - about their willpower are related to these outcomes. 


\section{WILLPOWER THEORIES AND DIABETES}

\section{Implicit Theories about Willpower}

The most prominent model in the self-control literature today is the strength model of self-control (Baumeister, Bratslavsky, Muraven, \& Tice, 1998; Baumeister et al., 2007). The model suggests that the capacity to self-control relies on a limited resource. Like a muscle that gets tired whilst training, the resource gets depleted during acts of self-control, such that subsequent self-control failure becomes more likely (Baumeister et al., 1998, 2007).

Challenging the idea of a limited resource, recent research suggests that how people respond to previous self-control demands depends on their beliefs_ — or implicit theories_-about willpower (Job, Dweck, \& Walton, 2010). Some people believe that their willpower is limited and gets easily depleted (they endorse a limited theory), whereas others believe that their willpower is not limited and can even get activated by previous self-control exertion (they endorse a nonlimited theory). Job and colleagues (2010) developed the Implicit Theories about Willpower Scale that assesses beliefs about willpower in two self-control domains, namely remaining in strenuous mental activities and resisting temptations. The scale includes items such as "Resisting temptations makes you feel more vulnerable to the next temptations that come along" (reflecting a limited theory) or "After you have resisted temptations your capacity to face upcoming temptations is still the same" (reflecting a nonlimited theory) (Job et al., 2010; Job, Walton, Bernecker, \& Dweck, 2015).

In a set of studies, Job and colleagues (2010) found that a limited theory is related to lower self-control performance. For instance, people who endorsed a limited theory performed worse in a self-control task (e.g., Stroop task), if they had previously worked on a different selfcontrol task (e.g., crossing out "e"s from a text according to a complicate rule). If the previous 


\section{WILLPOWER THEORIES AND DIABETES}

task did not require self-control (e.g., crossing out all "e"s from a text), people performed well on the second task, independent of their willpower theory.

This pattern of results was replicated with manipulated theories about willpower suggesting their causal role (Job et al., 2010; see also Miller et al., 2012). In these studies, participants filled in a biased questionnaire that fostered their agreement with a limited or nonlimited theory. Following this manipulation, they completed two subsequent self-control tasks. Participants who were let to endorse a limited theory were more likely to fail in the second self-control task than those who were let to endorse a nonlimited theory (Job et al., 2010). These findings suggest a causal relationship between willpower theories and continuous self-control performance and rule out the effect of third variables, such as ability or intelligence. To sum, the belief that willpower is a limited resource leads to self-control failure, particularly when selfcontrol has been previously challenged.

Corroborating these experimental findings, field studies document that willpower theories affect self-control performance in everyday life particularly in times when self-control demands are high. One study found that during the commencement of their final exams, students with a limited theory reported worse self-control performance (e.g., a less healthy diet) than their nonlimited fellows (Job et al., 2010, Study 4). In the middle of the semester, when self-control demands were low, willpower theories did not predict self-control performance (Job et al., 2010, Study 4). A recent study replicated these findings with a larger sample and assessed objective self-control outcomes, namely students' official grades (Job et al., 2015). Willpower theories predicted students' grade point average (controlling for previous grade point average), particularly among students with a high course load. Students with a limited theory performed worse than students with a nonlimited theory (Job et al., 2015). In sum, willpower theories 


\section{WILLPOWER THEORIES AND DIABETES}

predict self-control performance and academic achievement when people face high self-control demands.

Given the accumulating evidence on the impact of implicit willpower theories in the achievement context the present study aimed to test their relevance for real-world behavior in a different context in which self-control is crucial. Therapy adherence in people with type II diabetes is such a context. A typical diabetes therapy demands different behaviors that require self-control, such as monitoring blood sugar levels, taking medication regularly, dieting, or exercising (Hofmann, Friese, \& Wiers, 2008; Mann et al., 2013; Schroder \& Schwarzer, 2005). Accordingly, beliefs about willpower should be related to how well patients adhere to their therapy and should thereby also affect their psychological adjustment.

However, it is possible that over time people adjust to the demands implied by the disease, or develop routines and good self-care habits. According to dual-process theories a behavior can generally be guided by reflection (i.e., self-control) or automatic processes (i.e., habits; Rothman, Sheeran, \& Wood, 2009). Reflective processes are particularly important for the execution of new behavior. Over time when the same behavior is often repeated within the same context it gradually becomes habitual, that means automatically enacted in response to cues from the environment (Aarts, Paulussen, \& Schaalma, 1997). Thus, beliefs about willpower should be more important at the beginning of the disease when routines have yet to be established.

\section{Willpower Theories and Trait Self-control}

An important theoretical question is whether there is an incremental effect of beliefs about willpower over and above the effect of trait self-control. Trait self-control is defined as people's general capacity to exert self-control and is typically assessed with items such as "I am 


\section{WILLPOWER THEORIES AND DIABETES}

good at resisting temptations" or "I do certain things that are bad for me, if they are fun" (Tangney et al., 2004).

Trait self-control is associated with a range of positive outcomes, such as better eating and weight control and higher subjective well-being (Hofmann, Luhmann, Fisher, Vohs, \& Baumeister, 2013; Tangney et al., 2004; for a meta-analysis see de Ridder, Lensvelt-Mulders, Finkenauer, Stok, \& Baumeister, 2012). It should therefore also predict therapy adherence and well-being in people with diabetes.

As mentioned above, willpower theories refer to beliefs about the availability of selfcontrol particularly following previous self-control exertion. Thus, they capture a process-based view on self-control and how it changes in response to demands. In contrast, trait self-control assesses peoples' general self-control capacity independent of self-control demands (Tangney et al., 2004). This conceptual difference is supported by the recent finding that willpower theories and trait self-control are only moderately correlated (Job et al., 2015). So far, there is no evidence on the effects of willpower theories and trait self-control in the context of diabetes. Therefore, the present research explored the overlap between the two measures in a sample of diabetes patients and tested whether they have incremental predictive value for therapy adherence and well-being.

\section{The Present Research}

The present study examined the role of willpower theories for self-control and psychological adjustment in people with type 2 diabetes. We expected that endorsing a limited theory about willpower is associated with lower therapy adherence and lower psychological adjustment. Although, willpower theories should overlap with trait self-control to some degree, 


\section{WILLPOWER THEORIES AND DIABETES}

willpower theories should explain variance in self-control and psychological adjustment over and above patients' trait self-control.

Further, we expected that willpower theories have a stronger impact on self-control and psychological adjustment among newly diagnosed patients. Over time patients might develop routines, which substitute self-control. Therefore, willpower theories should be less important among patients with longer diabetes duration. To rule out that the effect of diabetes duration is not confounded with age or the presence of comorbid conditions both variables were assessed and controlled in the analyses.

\section{Method}

\section{Participants}

Seventy-nine diabetes type 2 patients ( 35 female, 44 male, $M=63.8$ years, Range: 28 87 years) were recruited in information centers, support groups, doctors surgeries in Germany and Switzerland and in online forums. To treat their condition 28 indicated taking medication, 16 taking insulin, 31 taking both, and 3 were only monitoring their diet and exercise.

\section{Procedure and Measures}

Participants filled in a 15-minute online or paper-pencil survey. Table 1 summarizes the descriptive statistics and reliability of the measures.

Implicit theories about willpower. Implicit theories about willpower were measured for three different self-control domains, namely strenuous mental activity, resisting temptations, and strenuous physical activity. The scale for strenuous mental activity and resisting temptations has previously been introduced by Job and colleagues (2010). For the purpose of this study we designed a new scale measuring willpower theories in the domain of strenuous physical activity (e.g., "After engaging in a strenuous physical task, your energy resources is usually depleted and 


\section{WILLPOWER THEORIES AND DIABETES}

you must rest to get it refueled again", $1=$ Strongly disagree to $6=$ Strongly agree). Each subscale was assessed with four items. The 12 items built a homogenous scale (see Table 1 for reliability information) and were thus averaged to a summary index of willpower theories. But we also tested whether the single subscales would predict behavior referring to the respective self-control domain (i.e., willpower theory on strenuous physical task predicting physical activity; willpower theory on resisting temptations predicting diet). High scores on each scale reflected greater agreement with a limited theory.

Trait self-control. Participants filled in the German version of the Trait Self-Control Scale (Bertrams \& Dickhäuser, 2009; Tangney et al., 2004) consisting of 13 items (e.g., "I am good at resisting temptations", $1=$ Not at all like me to $5=$ Very much like me).

Self-care activities. Participants answered seven items about their diabetes care within the past month (e.g., "Within the last month, how often did you control your blood sugar levels?", 1 = Less than once per day to 6 = Five or more times per day; ., "Within the last month, how often did you keep record of your blood sugar levels?", 1 = Never to 6 = Every day; "Within the last month, how often did you forget to take your diabetes medication/did you forget insulin injections?", 1 = Ca. once per day to 5 = Never; "Within the last month, how often did you have light hyper-/hypoglycemia?" 1 = Less than once per month to $5=$ Multiple times per day). Answers on each item were z-transformed and then averaged to one index of diabetes self-care with high values reflecting better self-care.

Diet and exercise. Four items taken from the Summary of Diabetes Self-Care Activities Measure (Toobert, Hampson, \& Glasgow, 2000) measured eating behavior (e.g., "How many of the last seven days have you followed a healthful eating plan?", 0 to 7) and two items measured frequency of physical exercise (e.g., "On how many of the last seven days did you participate in 


\section{WILLPOWER THEORIES AND DIABETES}

at least 30 minutes of physical activity? (Total minutes of continuous activity, including walking)", 0 to 7 ). The items were averaged for each scale.

Diabetes specific emotional distress. Emotional distress from diabetes was assessed with the Problem Areas in Diabetes Scale (Welche, Jacobson, \& Polonsky, 1997), which measures negative feelings related to the disease and its treatment, including worry, depressed mood, and fear. Two subscales with 14 items were administered (e.g., "Feeling constantly burned out by the constant effort to manage diabetes", $0=$ Minor problem to $4=$ Serious problem).

Subjective well-being. Five items of the German version of the WHO-5 scale (Brähler, Mühlan, Albani, \& Schmidt, 2007) assessed participants' well-being (e.g. 'Over the last two weeks...I have felt cheerful and in good spirits.”, $1=$ Never to $6=$ All the time).

Life quality. Participants rated their life quality on one item (i.e., "In general my current life quality (overall condition in current life situation) is...", $1=$ Very poor to $7=$ Excellent).

Body mass index. The body mass index (BMI) was calculated from two items assessing height and weight (i.e., "Please indicate your height (in m)/ weight (in kg): [open response]") by dividing the reported weight by the squared height.

Diabetes duration. Participants indicated the month and year they were diagnosed, which was used to calculate the number of years since the diagnosis.

Comorbid conditions. Presence of seven common comorbid conditions of diabetes type 2 were assessed (i.e., "cardiovascular disease"; "eye diseases”, "kidney disease”; "gum diseases/tooth decay", “skin diseases", "nervous diseases”, “other diseases”). Participants indicated the presence of each condition on a dichotomous scale $(0=$ No to $1=Y e s)$. 


\section{WILLPOWER THEORIES AND DIABETES}

\section{Results}

Table 1 displays the descriptive statistics and zero-order correlations of the main variables in the study. Willpower theories were moderately correlated with indicators of therapy adherence and indicators of psychological adjustment. As expected, people with a limited theory followed their therapy less well and indicated lower psychological adjustment (see Figure 1 a-d for scatterplots of the main correlations). Willpower theories were also related to participants' BMI. The more people endorsed a limited theory the higher was their BMI. This finding corroborates the idea that a limited theory is related to lower self-control in terms of dieting and might therefore also correlate with patients BMI. Replicating previous findings willpower theories were moderately related to levels of trait self-control (Job et al., 2015). The more people endorsed a limited theory about their willpower the higher was their trait self-control.

Next, we tested whether willpower theories were related to participants' therapy adherence and psychological adjustment when the effects of BMI and trait self-control were controlled for. We conducted six hierarchical regression analyses predicting the single outcome measures for therapy adherence and psychological adjustment by BMI and trait self-control in the first block, and willpower theory (either the total scale or the respective subscale) in the second block. All variables were z-standardized. The results are summarized in Table 2 . In the first block, trait self-control had small to medium effects on self-care activities and emotional distress. Higher trait self-control predicted better self-care and lower emotional distress. In the second block, endorsing a limited theory on the total willpower theory scale predicted lower therapy adherence (i.e., less self-care activities) and lower psychological adjustment (i.e., higher diabetes specific emotional distress, lower subjective well-being, and lower life quality). Further, a limited theory in the domain of resisting temptations was related to a less healthy diet, while a 


\section{WILLPOWER THEORIES AND DIABETES}

limited theory in the domain of strenuous physical exercise was related to less frequent physical exercise. Both outcomes were not predicted by the respective domain-unrelated subscale or by the total scale. According to Cohen (1988) the effect sizes of the variance explained by willpower theory $\left(f^{2}\right.$ Willpower Theory $)$ were small for the indicators of therapy adherence and large for indicators of psychological adjustment. Importantly, these effect sizes emerged over and above the effect of trait self-control. Unexpectedly, the effects of trait self-control on self-care and emotional distress consistently declined when willpower theories were added to the model.

Finally, we tested whether the effects of willpower theories were moderated by diabetes duration. Regression analyses were conducted to predict indicators of therapy adherence (i.e., self-care activities, diet, and exercise) and psychological adjustment (i.e., emotional distress, subjective well-being, life quality) by willpower theories, diabetes duration and their two-way interaction. To rule out confounding effects, age and the number of comorbid conditions were controlled in these regression models in addition to BMI and trait self-control. As expected, there was an interaction effect between willpower theory and diabetes duration on self-care activities, $\beta=.22$, se $=.07, f^{2}$ Interaction $=.05$, and emotional distress, $\beta=-.21, s e=.02, f^{2}$ Interaction $=.07$. The effect sizes of the interactions were small to medium (Cohen, 1988). The patterns of the interactions are depicted in Figure $2 \mathrm{a}$ and $2 \mathrm{~b}$. In both variables endorsing a nonlimited theory was more adaptive than a limited theory, particularly among patients who were shortly diagnosed with diabetes. Among patients with longer disease history there was no difference between patients with a limited and nonlimited theory. For the other four outcomes (i.e., diet, exercise, subjective well-being, and life quality) the interaction effects were small, $\beta<|.14|, f^{2}$ Interaktion $<$ .03. Here, a nonlimited theory was related to better outcomes, independent of diabetes duration. 


\section{WILLPOWER THEORIES AND DIABETES}

\section{General Discussion}

Based on previous evidence from experimental studies, showing that beliefs about willpower are important predictor for self-control, the present research examined whether beliefs about willpower affect important real-world outcomes related to self-control. Specifically, we examined the role of beliefs about willpower in the context of diabetes. Patients diagnosed with this disease face particularly high challenges of their self-control capacity to follow their diabetes regimen. Our findings suggests that among people with type 2 diabetes endorsing a limited theory about willpower is associated with lower therapy adherence and lower psychological adjustment. Participants with a limited theory reported less self-care activities, a less healthy diet, and lower levels of physical activity than people with a nonlimited theory. They further reported higher emotional distress from the disease, experienced lower subjective well-being, and higher life quality. Overall, the belief that willpower is nonlimited seems to be more adaptive for the adjustment to diabetes than the belief that willpower is limited. Importantly, the effects were independent of trait self-control, ruling out possible confounding effects.

Further, the effect of willpower theories on self-care activities was moderated by diabetes duration. The pattern of the interaction suggests that the impact of willpower theories decreases with longer diabetes duration. We suspect that over time self-care activities, such as regular blood sugar monitoring, become habitual, which means that they are automatically enacted and less dependent on reflective processes like self-control (Rothman et al., 2009). The effects of willpower theories on diet and exercise were both independent of diabetes duration, indicating that diet and exercise remain an issue of self-control even when people are diagnosed for a longer time. These findings are in line with previous intervention studies suggesting that 


\section{WILLPOWER THEORIES AND DIABETES}

people have a harder time to lastingly change their lifestyle in terms of diet and exercise than to develop self-care routines (Rubin, Peyrot, \& Saudek, 1991).

With regard to psychological adjustment the effects of willpower theories on subjective well-being and life quality were independent from diabetes duration - a limited theory was associated with lower well-being and life quality independent of duration. However, the effect of willpower theories on diabetes-specific emotional distress was dependent on diabetes duration. Newly diagnosed patients reported higher distress the more they believed that their willpower is limited. Among patients with longer disease history endorsing a limited theory was less harmful. This result parallels the findings for therapy adherence. Habits might ease the handling of the disease and thereby lower the levels of distress associated with it. However, to test these predictions, further studies are needed. Future studies should investigate the development of selfcare habits in type 2 diabetes patients using longitudinal designs and examine whether the formation of habits explains the weaker influence of willpower theories over time.

An unexpected outcome of the present study was that the effect of trait self-control on self-care activities and diabetes-related distress was reduced when willpower theories were controlled for. This finding could be taken to suggest that willpower theories are part of the mechanism explaining why high trait self-control is adaptive for therapy adherence and diabetesrelated distress. Hence, the finding raises the question whether previously documented effects of trait self-control on performance and psychological adjustment in other samples might at least in part be explained by adaptive beliefs about willpower. However, due to the correlational nature of the present study we cannot make any claims about the direction of causality or mediational processes (Fiedler, Schott, \& Meiser, 2011). Although previous experimental work corroborates the idea that beliefs about willpower affect self-control performance (Job et al., 2010), it is likely 


\section{WILLPOWER THEORIES AND DIABETES}

that the link between beliefs and self-control performance is bi-directional. A history of selfcontrol failure or success and/or recent experiences of either one should also affect a person's beliefs. More research is needed to explore the relationship between past self-control behavior and people's beliefs about willpower.

The increasing prevalence of diabetes and the severe consequences of low treatment adherence for people's health and longevity (Andersson \& Svärdsudd, 1995; Klein et al., 1996), stresses the importance of identifying psychological factors that relate to patients' therapy adherence and psychologically adjustment. The present study is the first to demonstrate that beliefs about willpower, a socially shaped, psychological variable might be of considerable importance for therapy adherence and psychological adjustment in people with type 2 diabetes. 


\section{WILLPOWER THEORIES AND DIABETES}

\section{Footnotes}

${ }^{1}$ The scale for strenuous physical activity was developed for this study. The items can be requested from the authors. 


\section{WILLPOWER THEORIES AND DIABETES}

\section{Compliance with Ethical Standards}

The authors declare that they have no conflict of interest.

All procedures performed in studies involving human participants were in accordance with the ethical standards of the institutional research committee and with the 1964 Helsinki declaration and its later amendments or comparable ethical standards. This article does not contain any studies with animals performed by any of the authors.

Informed consent was obtained from all individual participants included in the study.

\section{Acknowledgements}

We are grateful to Veronika Brandstätter for her comments on a previous version of this manuscript. 


\section{WILLPOWER THEORIES AND DIABETES}

\section{References}

Aarts, H., Paulussen, T., \& Schaalma, H. (1997). Physical exercise habit: on the conceptualization and formation of habitual health behaviours. Health Education Research, 12(3), 363-374. doi:10.1093/her/12.3.363

Adriaanse, M. A., Kroese, F. M., Gillebaart, M., \& De Ridder, D. T. D. (2014). Effortless inhibition: habit mediates the relation between self-control and unhealthy snack consumption. Frontiers in Psychology, 5(444), 1-6. doi:10.3389/fpsyg.2014.00444

American Diabetes Association. (2008). Diagnosis and classification of diabetes mellitus. Diabetes Care, 31, S55-60. doi:10.2337/dc08-S055

Andersson, D. K. G., \& Svärdsudd, K. (1995). Long-Term glycemic control relates to mortality in type II diabetes. Diabetes Care, 18(12), 1534-1543.

Baumeister, R. F., Bratslavsky, E., Muraven, M., \& Tice, D. M. (1998). Ego depletion: is the active self a limited resource? Journal of Personality and Social Psychology, 74(5), 125265. doi:10.1037/0022-3514.74.5.1252

Baumeister, R. F., Vohs, K. D., \& Tice, D. M. (2007). The strength model of self-control. Current Directions in Psychological Science, 16(6), 351-355. doi:10.1111/j.14678721.2007.00534.x

Bertrams, A., \& Dickhäuser, O. (2009). Messung dispositioneller Selbstkontroll-Kapazität. Diagnostica, 55(1), 2-10. doi:10.1026/0012-1924.55.1.2 


\section{WILLPOWER THEORIES AND DIABETES}

Boule, N. G., Haddad, E., Kenny, G. P., Wells, G. A., \& Sigal, R. J. (2001). Effects of exercise on glycemic control and body mass in type 2 diabetes mellitus: A meta-analysis of controlled clinical trials. Journal of the American Medical Association, 286(10), 12181227.

Brähler, E., Mühlan, H., Albani, C., \& Schmidt, S. (2007). Teststatistische Prüfung und Normierung der deutschen Versionen des EUROHIS-QOL Lebensqualität-Index und des WHO-5 Wohlbefindens-Index. Diagnostica, 53(2), 83-96. doi:10.1026/0012-1924.53.2.83

Brand-Miller, J., Petocz, P., Hayne, S., \& Colagiuri, S. (2003). Low - glycemic index diets in the management of diabetes: A meta-analysis of randomized controlled trials. Diabetes Care, 26(8), 2261-2267.

Cohen, J. (1988). Statistical power analyis for the behavioral sciences (2nd Ed.). Hillsdale, NJ: Lawrence Erlbaum Associates Publishers.

De Ridder, D. T. D., Lensvelt-Mulders, G., Finkenauer, C., Stok, F. M., \& Baumeister, R. F. (2012). Taking stock of self-control: a meta-analysis of how trait self-control relates to a wide range of behaviors. Personality and Social Psychology Review : An Official Journal of the Society for Personality and Social Psychology, Inc, 16(1), 76-99. doi: $10.1177 / 1088868311418749$

Fiedler, K., Schott, M., \& Meiser, T. (2011). What mediation analysis can (not) do. Journal of Experimental Social Psychology, 47(6), 1231-1236. doi:10.1016/j.jesp.2011.05.007 


\section{WILLPOWER THEORIES AND DIABETES}

Finkel, E. J., DeWall, C. N., Slotter, E. B., Oaten, M., \& Foshee, V. a. (2009). Self-regulatory failure and intimate partner violence perpetration. Journal of Personality and Social Psychology, 97(3), 483-499. doi:10.1037/a0015433

Fishbach, A., \& Shah, J. Y. (2006). Self-control in action: implicit dispositions toward goals and away from temptations. Journal of Personality and Social Psychology, 90(5), 820-832. doi:10.1037/0022-3514.90.5.820

Fujita, K. (2011). On conceptualizing self-control as more than the effortful inhibition of impulses. Personality and Social Psychology Review, 15(4), 352-66. doi: $10.1177 / 1088868311411165$

Hofmann, W., Friese, M., \& Wiers, R. W. (2008). Impulsive versus reflective influences on health behavior: a theoretical framework and empirical review. Health Psychology Review, 2(2), 111-137. doi:10.1080/17437190802617668

Hofmann, W., Gschwendner, T., Friese, M., Wiers, R. W., \& Schmitt, M. (2008). Working memory capacity and self-regulatory behavior: toward an individual differences perspective on behavior determination by automatic versus controlled processes. Journal of Personality and Social Psychology, 95(4), 962-977. doi:10.1037/a0012705

Hofmann, W., Luhmann, M., Fisher, R. R., Vohs, K. D., \& Baumeister, R. F. (2013). Yes, but are they happy? Effects of trait self-control on affective well-being and life satisfaction. Journal of Personality, 1-13. doi:10.1111/jopy.12050 


\section{WILLPOWER THEORIES AND DIABETES}

Job, V., Dweck, C. S., \& Walton, G. M. (2010). Ego depletion--is it all in your head? Implicit theories about willpower affect self-regulation. Psychological Science, 21(11), 1686-93. doi:10.1177/0956797610384745

Job, V., Walton, G. M., Bernecker, K., \& Dweck, C. S. (2015). Implicit theories about willpower predict self-regulation and grades in everyday life. Journal of Personality and Social Psychology, 108(4), 637-647.

Klein, R., Klein, B. E. K., \& Moss, S. E. (1996). Relation of glycemic control to diabetic microvascular complications in diabetes mellitus. Annals of Internal Medicine, 124(1), 9196.

Mann, T., de Ridder, D., \& Fujita, K. (2013). Self-regulation of health behavior: social psychological approaches to goal setting and goal striving. Health Psychology, 32(5), 48798. doi:10.1037/a0028533

Miller, E. M., Walton, G. M., Dweck, C. S., Job, V., Trzesniewski, K. H., \& McClure, S. M. (2012). Theories of willpower affect sustained learning. PloS One, 7(6), e38680. doi:10.1371/journal.pone.0038680

Moffitt, T. E., Arseneault, L., Belsky, D., Dickson, N., Hancox, R. J., Harrington, H., ... Caspi, A. (2011). A gradient of childhood self-control predicts health, wealth, and public safety. Proceedings of the National Academy of Sciences of the United States of America, 108(7), 2693-8. doi:10.1073/pnas.1010076108 


\section{WILLPOWER THEORIES AND DIABETES}

Rothman, A. J., Sheeran, P., \& Wood, W. (2009). Reflective and automatic processes in the initiation and maintenance of dietary change. Annals of Behavioral Medicine, 38(1), S4-17. doi:10.1007/s12160-009-9118-3

Rubin, R. R., \& Peyrot, M. (1999). Quality of life and diabetes. Diabetes/metabolism Research and Reviews, 15(3), 205-18. Retrieved from http://www.ncbi.nlm.nih.gov/pubmed/10441043

Rubin, R. R., Peyrot, M., \& Saudek, C. D. (1991). Differential effect of diabetes education on self-regulation and life-style behaviors. Diabetes Care, 14(4), 335-338. doi:10.2337/diacare.14.4.335

Schroder, K. E. E., \& Schwarzer, R. (2005). Habitual self-control and the management of health behavior among heart patients. Social Science \& Medicine, 60(4), 859-875. doi:10.1016/j.socscimed.2004.06.028

Shaw, J. E., Sicree, R. A., \& Zimmet, P. Z. (2010). Global estimates of the prevalence of diabetes for 2010 and 2030. Diabetes Research and Clinical Practice, 87(1), 4-14. doi:10.1016/j.diabres.2009.10.007

Shoda, Y., Mischel, W., \& Peake, P. K. (1990). Predicting adolescent cognitive and selfregulatory competencies from preschool delay of gratification: Identifying diagnostic conditions. Developmental Psychology, 26(6), 978-986. doi:10.1037//0012-1649.26.6.978 


\section{WILLPOWER THEORIES AND DIABETES}

Stadler, G., Oettingen, G., \& Gollwitzer, P. M. (2010). Intervention effects of information and self-regulation on eating fruits and vegetables over two years. Health Psychology, 29(3), 274-83. doi:10.1037/a0018644

Tangney, J. P., Baumeister, R. F., \& Boone, A. L. (2004). High self-control predicts good adjustment, less pathology, better grades, and interpersonal success. Journal of Personality, 72(2), 271-324. doi:10.1111/j.0022-3506.2004.00263.x

Toobert, D. J., Hampson, S. E., \& Glasgow, R. E. (2000). The summary of diabetes self-care activities measure. Diabetes Care, 23(7), 943-950. doi:10.2337/diacare.23.7.943

Turner, R. C., Cull, C. A., \& Frighi, V. (1999). Glycemic control with diet, sulfonylurea, metformin, or insulin in patients with type 2 diabetes mellitus: Progressive requirement for multiple therapies. Journal of the American Dietetic Association, 281(21), 2005-2012. doi:10.1001/jama.281.21.2005

Van der Does, F. E. E., De Neeling, J. N. D., Snoek, F. J., Kostense, P. J., Grootenhuis, P. A., Bouter, L. M., \& Heine, R. J. (1996). Symptoms and well-being in relation to glycemic control in type II diabetes. Diabetes Care, 19(3), 204-210.

Welche, G. W., Jacobson, A. M., \& Polonsky, W. H. (1997). The problem areas in diabetes scale: An evaluation of its clinical utility. Diabetes Care, 20(5), 760-766. doi:10.2337/diacare.20.5.760 
Table 1

Descriptive Statistics and Zero-Order Correlations of the Main Variables

\begin{tabular}{|c|c|c|c|c|c|c|c|c|c|c|c|c|c|c|c|}
\hline Variable & $\alpha$ & $M$ & $S D$ & Min & $\operatorname{Max}$ & 1 & 2 & 3 & 4 & 5 & 6 & 7 & 8 & 9 & 10 \\
\hline 1. Willpower Theory & .80 & 3.45 & 0.77 & 1.40 & 6.00 & & & & & & & & & & \\
\hline 2. Self-Care Activities ${ }^{\mathrm{a}}$ & - & 0.16 & 0.54 & -1.64 & 1.20 & -.26 & & & & & & & & & \\
\hline 3. Diet & .67 & 5.73 & 1.41 & 0.00 & 7.00 & -.10 & .10 & & & & & & & & \\
\hline 5. Diabetes Specific Emotional Distress ${ }^{b}$ & .92 & 0.25 & 0.16 & 0.00 & 0.70 & .48 & -.16 & -.08 & -.07 & & & & & & \\
\hline 6. Subjective Well-Being & .92 & 4.12 & 1.23 & 1.40 & 6.00 & -.53 & .09 & .00 & .44 & -.47 & & & & & \\
\hline 7. Life Quality & - & 4.97 & 1.04 & 3.00 & 7.00 & -.47 & .12 & .02 & .34 & -.56 & .76 & & & & \\
\hline 10. Diabetes Duration & - & 15.53 & 12.06 & 0.17 & 44.74 & -.12 & .19 & .15 & .05 & -.14 & .24 & .21 & -.04 & -.03 & \\
\hline 11. Comorbid Conditions & - & 0.96 & 1.20 & 1.00 & 5.00 & -.02 & .16 & -.01 & -.11 & .13 & -.23 & -.18 & .06 & -.04 & .05 \\
\hline
\end{tabular}

Note. Higher scores reflected greater agreement with a limited theory, higher trait self-control, better self-care, healthier diet, more exercise, higher subjective well-being, higher life quality, more diabetes specific distress. BMI $=$ body mass index.

${ }^{a}$ Scale from different z-tranformed indicators. ${ }^{b}$ Scale was log-transformed to correct for skewness. 
Table 2

Hierarchical Regression Analyses Predicting Therapy Adherence and Psychological Adjustment from Body Mass Index, Trait Self-Control And Implicit Theories about Willpower

\begin{tabular}{|c|c|c|c|c|c|c|c|c|c|c|c|c|}
\hline \multirow[b]{3}{*}{ Predictor } & \multicolumn{6}{|c|}{ Measures of Diabetes Management } & \multicolumn{6}{|c|}{ Measures of Psychological Adjustment } \\
\hline & \multicolumn{2}{|c|}{ Self-Care } & \multicolumn{2}{|c|}{$\operatorname{Diet}^{\mathrm{a}}$} & \multicolumn{2}{|c|}{ Exercise $^{\mathrm{b}}$} & \multicolumn{2}{|c|}{$\begin{array}{c}\text { Emotional } \\
\text { Distress }\end{array}$} & \multicolumn{2}{|c|}{$\begin{array}{l}\text { Subjective } \\
\text { Well-Being }\end{array}$} & \multicolumn{2}{|c|}{ Life Quality } \\
\hline & $\Delta R^{2}$ & $\beta$ & $\Delta R^{2}$ & $\beta$ & $\Delta R^{2}$ & $\beta$ & $\Delta R^{2}$ & $\beta$ & $\Delta R^{2}$ & $\beta$ & $\Delta R^{2}$ & $\beta$ \\
\hline Step 1 & .08 & & .10 & & .17 & & .17 & & .06 & & .09 & \\
\hline BMI & & .18 & & -.21 & & -.46 & & .23 & & -.12 & & -.22 \\
\hline Trait Self-Control & & .19 & & .19 & & -.05 & & -.30 & & .19 & & .14 \\
\hline Step 2 & .06 & & .03 & & .05 & & .12 & & .19 & & .15 & \\
\hline BMI & & -.21 & & -.19 & & -.43 & & .18 & & -.06 & & -.17 \\
\hline Trait Self-Control & & .16 & & .10 & & -.14 & & -.13 & & -.01 & & -.04 \\
\hline Willpower Theory & & -.28 & & -.21 & & -.21 & & .40 & & -.50 & & -.44 \\
\hline$f^{2}$ Willpower Theory & .07 & & .03 & & .06 & & .17 & & .25 & & .20 & \\
\hline
\end{tabular}

Note. Higher scores reflected higher BMI, higher trait self-control, greater agreement with a limited theory, better self-care, healthier diet, more frequent exercise, higher emotional distress, better subjective well-being, and better life quality. BMI=Body Mass Index.

${ }^{a}$ Subscale of willpower theory for resisting temptations used for the analysis. ${ }^{b}$ Subscale of willpower theory for strenuous physical activity used in the analysis. 


\section{WILLPOWER THEORIES AND DIABETES}

\section{Figure Captions}

Figure 1. Scatterplots of correlations between willpower theory and a) therapy adherence, b) subjective well-being, c) emotional distress, and d) trait self-control.

Figure 2. Effects of implicit theories about willpower on a) self-care activities and b) diabetes specific emotional distress moderated by diabetes duration (controlling for age). Error bars indicate $+/-1 S E$. 


\section{WILLPOWER THEORIES AND DIABETES}

a
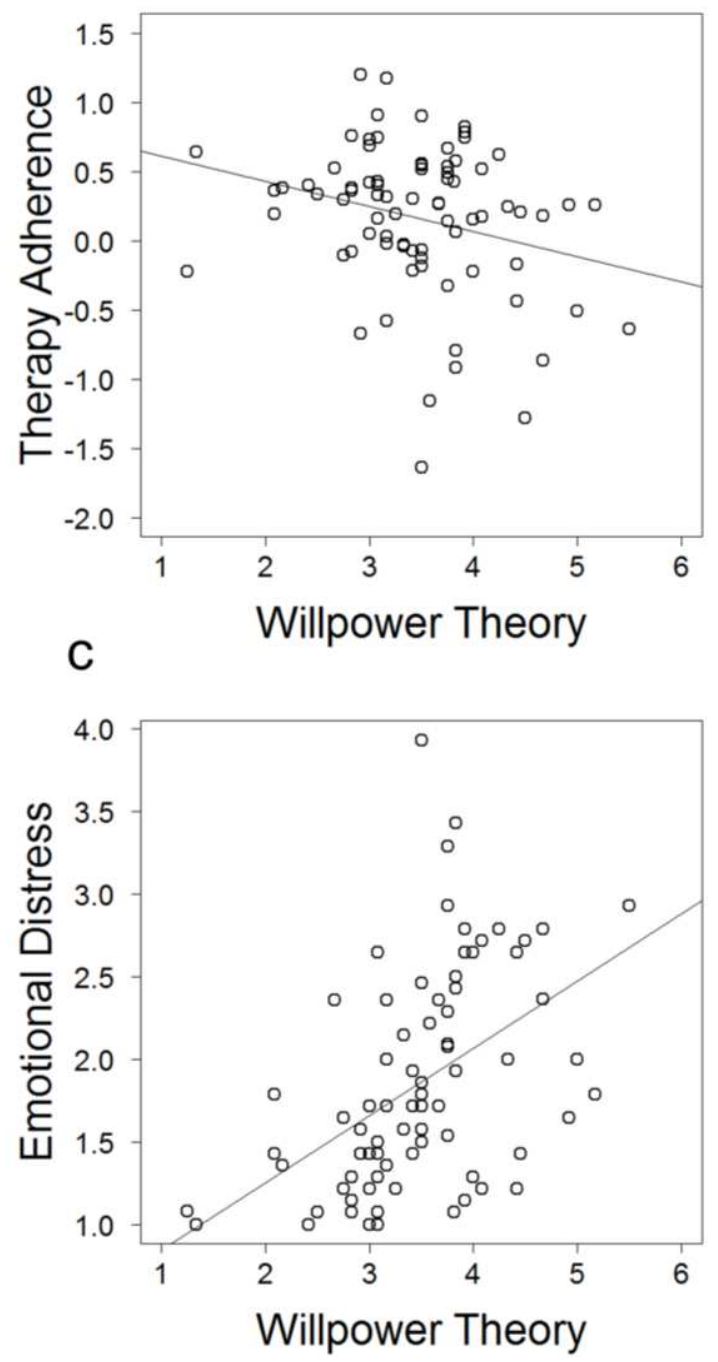

b
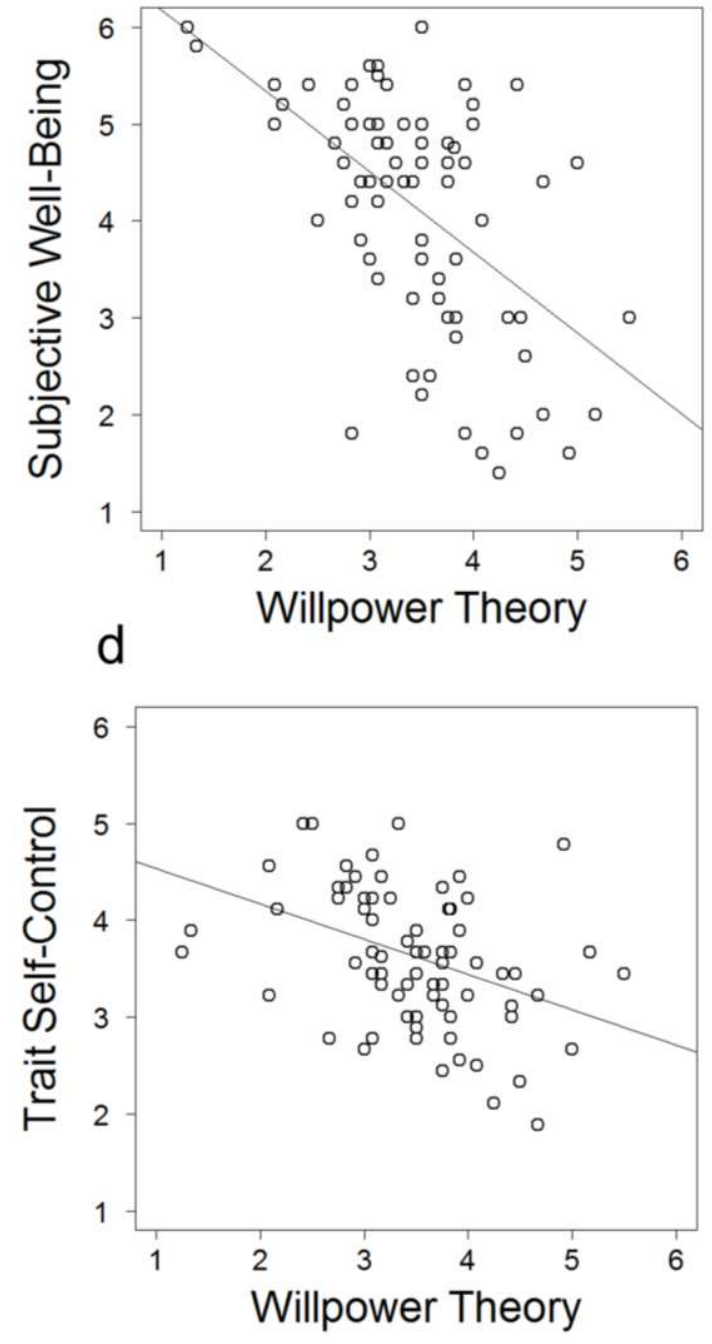

Figure 1 


\section{WILLPOWER THEORIES AND DIABETES}

a

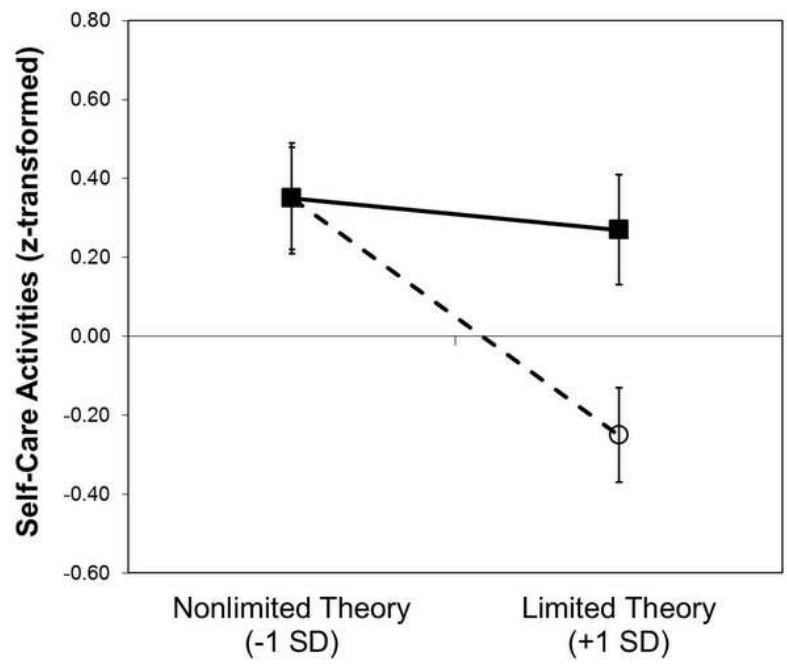

b

--Long Diabetes Duration (+1 SD)

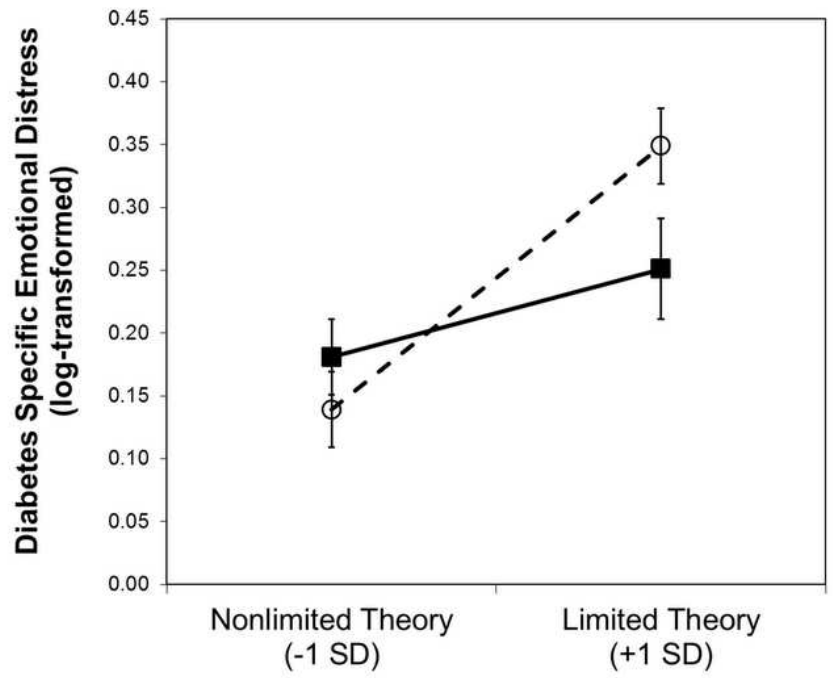

Figure 2 